\title{
Covered Stent Treatment of Coronary Aneurysm in an Octogenarian
}

\author{
Kiran Siddavaram \\ Department of Cardiology, Saideep Healthcare and Research Private Limited, Ahmednagar, Maharashtra, India \\ ORCID: \\ Kiran Siddavaram: https://orcid.org/0000-0003-4905-2584
}

\section{Abstract}

Coronary artery aneurysms are rare cardiac entities that may remain clinically silent throughout life. However, failure to diagnose and treat these cardiac entities could prove fatal due to their tendency to rupture, thrombose, or embolize. Here, we present the case of an octogenarian who presented with $90 \%$ stenosis in the left descending coronary artery accompanied by a coronary artery aneurysm.

Keywords: Coronary artery aneurysm, covered stent, octogenarian

\section{INTRODUCTION}

Coronary artery aneurysms are identified as abnormal dilatations of the coronary vessel diameter at least 1.5 times greater than normal adjacent segments of the vessel. ${ }^{[1]}$ These are often incidental angiographic findings observed in up to $5 \%$ of patients undergoing coronary angiography. The vast majority of patients remain asymptomatic throughout their life. Incidence ranges from $0.3 \%$ to $5.0 \%{ }^{\left[{ }^{2]}\right.}$

\section{Case Report}

An 85-year-old female presented to our tertiary-care center with chest pain of 1-day duration. She was a known case of unstable angina. Hypertension was not suspected as the patient always presented with normal blood pressure. Hyperlipidemia was investigated for, yet levels were normal. No investigations for connective tissue disorder were performed. Laboratory findings indicated troponin levels of $1.0 \mathrm{ng} / \mathrm{ml}$, creatinine levels of $0.8 \mathrm{mg} / \mathrm{dl}$, and hemoglobin levels of $10 \mathrm{~g} / \mathrm{dL}$. Coronary angiography performed 7 years earlier revealed $90 \%$ stenosis in the proximal left anterior descending (LAD) coronary artery with an aneurysm and mild stenosis in the obtuse marginal artery. Echocardiography performed 3 years

Received: 03-02-2021 Revised: 23-06-2021 Accepted: 30-06-2021 Published Online: 25-09-2021

\begin{tabular}{|l|l|}
\hline \multicolumn{3}{|c|}{ Access this article online } \\
\hline Quick Response Code: & Website: \\
& \\
http://www.ijcva.com
\end{tabular}

earlier indicated left ventricular hypertrophy, left ventricular diastolic dysfunction, 56\% left ventricular ejection fraction, and Grade 1 aortic, mitral, and tricuspid regurgitation. The patient was advised percutaneous transluminal coronary angioplasty to the LAD. However, the patient did not undergo the advised treatment at the time due to financial constraints. Recently, investigations performed at our tertiary-care center confirmed earlier angiographic findings of $90 \%$ stenosis in proximal LAD with a saccular aneurysm measuring $3.5 \mathrm{~mm} \times 2.0 \mathrm{~mm}$ [Figure 1a] and echocardiographic findings of left ventricular hypertrophy, left ventricular diastolic dysfunction, 60\% left ventricular ejection fraction, and atherosclerotic aortic regurgitation Grade 1. It was elected to exclude the aneurysm through the implantation of a covered stent.

After engaging a 6F EBU guiding catheter, a Fielder FC and Run-through wire crossed the lesion [Figure 1b]. The lesion was predilated with $1.5 \mathrm{~mm} \times 10 \mathrm{~mm}$ and $2.0 \mathrm{~mm} \times 15 \mathrm{~mm}$ Sprinter Balloons and negotiated with $2.8 \mathrm{~mm} \times 19 \mathrm{~mm}$ polytetrafluoroethylene-covered stent (Graftmaster, Abbott Vascular, Santa Clara, California) [Figure 1c]. The stent was

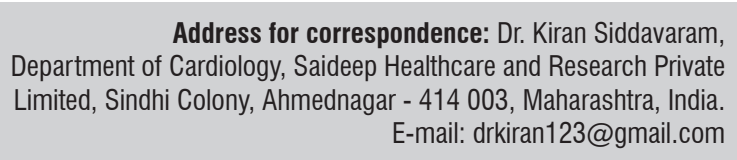

This is an open access journal, and articles are distributed under the terms of the Creative Commons Attribution-NonCommercial-ShareAlike 4.0 License, which allows others to remix, tweak, and build upon the work non-commercially, as long as appropriate credit is given and the new creations are licensed under the identical terms.

For reprints contact: WKHLRPMedknow_reprints@wolterskluwer.com

How to cite this article: Siddavaram K. Covered stent treatment of coronary aneurysm in an octogenarian. Int J Cardiovasc Acad 2021;7:103-5. 


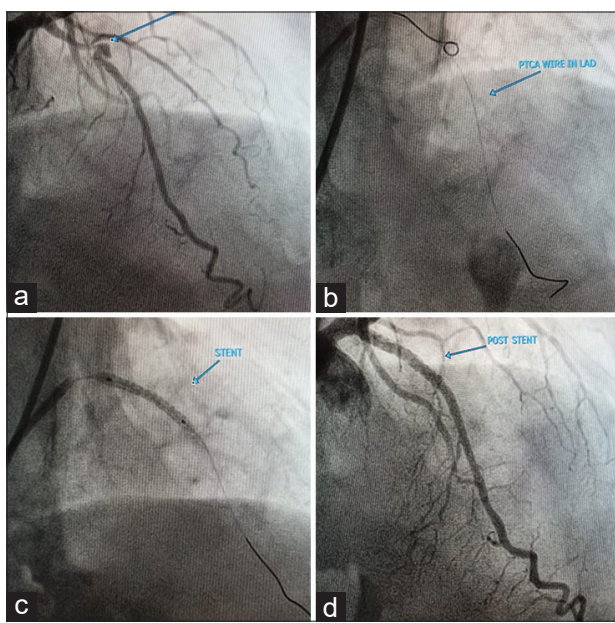

Figure 1: Coronary angiography revealing: (a) 90\% proximal stenosis in left anterior descending coronary artery; (b) lesion engaged with 6F EBU guiding catheter and crossed with Fielder FC and Runthrough wire; (c) lesion predilation with $1.5 \mathrm{~mm} \times 10 \mathrm{~mm}$ and $2.0 \mathrm{~mm} \times 15 \mathrm{~mm}$ with Sprinter Balloons and negotiation with $2.80 \mathrm{~mm} \times 19 \mathrm{~mm}$ Graftmaster stent; and (d) stent postdilatation with a $3.0 \mathrm{~mm} \times 8 \mathrm{~mm}$ Euphora Balloon. Good poststent TIMI III flow was achieved

postdilated with a $3.0 \mathrm{~mm} \times 8.0 \mathrm{~mm}$ Euphora Balloon. Good poststent Thrombolysis in Myocardial Infarction (TIMI) III flow was achieved [Figure 1d]. No glycoprotein IIb/IIIa class platelet inhibitors were administered after the procedure.

\section{DISCUSSION}

Coronary artery aneurysms are rare occurrences with clinical presentations ranging from asymptomatic to acute coronary syndrome. Although precise pathogenesis is yet to be delineated, a few hypotheses based on associations and specific risk factors have been cited in the current literature. These are:

1. Individual genetic predisposition to develop coronary artery aneurysms

2. Association between coronary artery aneurysms and coronary artery disease suggestive of underlying etiology

3. Vasculitis and connective tissue disorders such as Kawasaki disease and Marfan syndrome have evidenced correlation with coronary artery aneurysms

4. Arterial wall injury caused during stent implantation and other percutaneous coronary interventions has been reported to provoke the formation of coronary artery aneurysms. Notably, this has been mostly observed with earlier generation drug-eluting stents and seldomly with the second-and third-generation drug-eluting stents. ${ }^{[2]}$

Our patient did not undergo drug-eluting stent implantation in the past, thus ruling out the possibility of this common etiology. Atherosclerosis is the most common underlying etiology of coronary artery aneurysms. In some cases, atherosclerotic coronary artery aneurysms may mirror clinical features and risk factors related to coronary artery disease. ${ }^{[3]}$ Our patient presented with $90 \%$ stenosis in the left descending coronary artery within proximity of the aneurysm. Several other cases have documented the accompaniment of aneurysms by extensive atherosclerosis in the same vessel. ${ }^{[4,5]}$ Furthermore, her advanced age further fortifies this hypothesis of coronary artery disease as an underlying etiology.

Current literature asserts coronary artery aneurysms have a propensity to occur more often in the proximal rather than distal segments of the coronary tree. Furthermore, saccular aneurysms occur more frequently in LAD than any other branch of the coronary tree. All these assertions hold true in the present case. ${ }^{[6]}$

Current treatment strategies for coronary artery aneurysms include conservative medical therapy, coil embolization, percutaneous covered stent implantation, and more aggressive surgical resection or ligation procedures. ${ }^{[3,4]}$ There are no guidelines or consensus outlining the optimal management of these clinical entities owing to the lack of randomized controlled trials. Current literature exists in the form of case series or anecdotal reports; thus treatment mandates a patient-specific approach taking into account clinical and angiographic factors. Medical therapy, although a conservative approach, is debatable with no evidence to either support or refute this strategy. ${ }^{[2]}$ Coil embolization is a feasible technique if the structure of the aneurysm permits. These coils form a barrier against inflow from the parent artery ultimately curbing the risk of rupture. ${ }^{[1]}$ Surgical treatment is preferred in cases of left main involvement or giant coronary artery aneurysms as these are particularly challenging. ${ }^{[1,2,5]}$ Covered stents implanted at the site of the aneurysm impede blood flow to the aneurysmal sac. The synthetic membrane of the stent graft also averts plaque protrusion while sealing off the aneurysm. Expansion 4-5 times its original diameter without laceration or shrinkage is feasible. Moreover, negative charge of the polymer prevents blood-protein coagulation on the tissue surface, limiting platelet activation, and thrombus formation. ${ }^{[4]}$ Lastly, as observed in the present case, these cardiac implants also provide the opportunity to simultaneously address underlying atherosclerosis in the same vessel. All these features make covered stents an easy, safe, rapid, and minimally invasive treatment alternative. The advanced age of our patient deemed her a high-risk patient unfit for surgical intervention. Therefore, in light of the size and shape of the aneurysm, it was decided to treat the patient through implantation of a covered stent to exclude the aneurysm.

\section{ConcLusion}

The patient-specific treatment strategies should be elected in patients with coronary artery aneurysms. Patient age, comorbidities, aneurysm size, and shape should be considered. Advanced age, saccular shape, and size of the aneurysm made covered stent implantation feasible in our 85-year-old female patient.

\section{Declaration of patient consent}

The authors certify that they have obtained all appropriate patient consent forms. In the form the patient(s) has/have 
given his/her/their consent for his/her/their images and other clinical information to be reported in the journal. The patients understand that their names and initials will not be published and due efforts will be made to conceal their identity, but anonymity cannot be guaranteed.

\section{Financial support and sponsorship}

Nil.

\section{Conflicts of interest}

There are no conflicts of interest.

\section{RefEREnCES}

1. Shridhar P, Smith T, Khalil R, Lasorda D, Chun Y. Exclusion of giant coronary artery aneurysm with covered stent combined with coil embolization of vessel outflow. Med Case Rep (Wilmington) 2016;2:1-3.

2. Kawsara A, Gil IJ, Alqahtani F, Moreland J, Rihal CS, Alkhouli M. Management of coronary artery aneurysms. JACC Cardiovasc Interv 2018;11:1211-23.

3. Lawani O, Ganim R. Unique findings and novel treatment strategy of a giant coronary artery aneurysm associated with a significant pericardial effusion. Case Rep Cardiol 2020;2020:8890806.

4. Bajaj S, Parikh R, Hamdan A, Bikkina M. Covered-stent treatment of coronary aneurysm after drug-eluting stent placement: case report and literature review. Tex Heart Inst J 2010;37:449-54.

5. Cotter R, Krantz M, Hogan S, Holland M. Exclusion of a giant coronary artery aneurysm with covered stents using a long drug-eluting stent scaffold. Clin Med Insights Case Rep 2019;12:1179547619828689.

6. Ruiz-Nodar JM, Valencia J, Pineda J. Coronary aneurysms after drug-eluting stents implantation. Eur Heart J 2007;28:2826. 